\title{
Referentes clonados ou corpos ambiguamente habitados
}

Denize Correa Araujo Universidade Tuiuti do Paraná /UTP 


\section{Resumo}

O objetivo deste ensaio é investigar como a ambigüidade do textocolagem Las Meninas, de Valêncio Xavier e Rones Dumke, funciona em seu "escrever com textos"(Landow). Minha hipótese é de que o uso deliberado da ambigüidade ou problematiza ou "brinca "com os elementos hierárquicos. Ou ambos. O trabalho de Xavier-Dumke é um texto híbrido, composto de três contos que interagem com Las Meninas de Velásquez e criam interfaces verbais e não-verbais, sem procurar escrever sobre o original, mas sim escrevendo junto com esse. Se o original de Velázquez já questiona a natureza da representação, o texto aqui analisado também o faz, duplamente, desconstruindo os valores tradicionais da Corte. A leitura que proponho evidencia a "estética da hipervenção", gerando uma autoreflexividade, aqui abordada com base nos conceitos e teorias póscolonialistas e pós-modernistas de Thab Hassan, Fredric Jameson, Lucia Santaella e George Landow.

\section{Palavras-chave}

"estética da hipervenção", auto-reflexividade, texto híbrido

\section{Abstract}

This essay intends to investigate how ambiguity in Valêncio Xavier and Rones Dumke's collage-text entitled Las Meninas works within its "writing with texts" (Landow). My hypothesis is that the use of ambiguity either problematizes or "plays" with hierarchical elements. Or both. Xavier-Dumke's composite is a hybrid text, integrating a visual parody and three short stories that interact with Velázquez' Las Meninas and create verbal and non-verbal interfaces. If the original by Velázquez already questions the nature of representation, the text analized here does it too, deconstructing traditional values. The reading I propose emphasizes the "hipervention aesthetics", contributing to a self reflexivity studied here through the postcolonialist and postmodernist concepts and theories by thab Hassan, Fredric Jameson, Lucia Santaella and George Landow.

\section{Key words}

"aesthetics of hypervention", self-reflexivity, hybrid text 


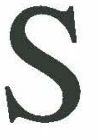

e Diego Velázquez antecipou técnicas da fotografia, metalingüisticamente criando uma ambigüidade capaz de encorajar leituras diferenciadas, o que se pode então dizer do texto-colagem de Rones Dumke e Valêncio Xavier?

Apesar de o conceito de colagem não ser novo, Greg Ulmer, em seu artigo "The Object of Post-Criticism"(20), acredita que o método de colagem é a inovação formal singular mais revolucionária que ocorreu na representação artística de nosso século, caracterizando-se pela remoção de elementos de seus con-

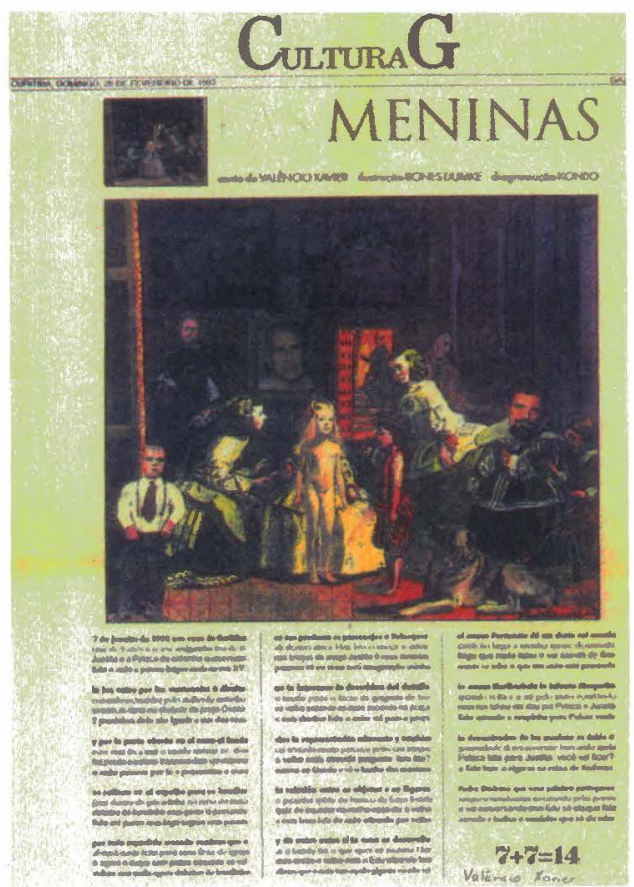

textos originais e pela montagem de fragmentos em novas configurações (Ulmer 84). A idéia da colagem, de acordo com Robert Hugues, em seu livro The Shock of the $\mathrm{New}$, existiu na arte folclórica durante todo o século XX, especialmente em quartos de crianças e escolas maternais de classe média, que tinham suas paredes decoradas com querubins, animais e flores retiradas de revistas (32).

A colagem intertextual no pós-modernismo, porém, difere das definições prévias e se insere melhor na sugestão de George P. Landow: 
Colagem ou efeitos-colagem, de fato parecem inevitáveis em contextos de hipertexto, tomando várias formas. A inclusäo de blocos de textos ou imagens de não-ficção dentro de um hipertexto de ficção, como já vimos, evidencia uma das maneiras onde tal colagem ocorre; isso também acontece quando autores escrevem com e, poder-se-ia dizer, junto com textos de outros. (37-38)

Este parece ser o caso dos brasileiros Valêncio Xavier e Rones Dumke (Xavier-Dumke para mais fácil identificação), cujo conto-colagem foi escrito e ilustrado não sobre mas junto com a obra Las Meninas de Velázquez, reiterando a jocosa ambigüidade original.

O objetivo deste estudo é investigar como essa ambigüidade funciona em seu "escrever junto com textos". Minha suposição é que o uso deliberado da ambigüidade ou problematiza ou "brinca" com os elementos hierárquicos. Ou ambos. A montagem de XavierDumke, disposta em camadas, pode provocar leituras controvertidas além de alterar os elementos envolvidos.

O trabalho de Xavier-Dumke tem por texto-base o famoso Las Meninas de Diego Velázquez e é um texto híbrido: três contos entremeados e ilustrados. Embora tudo esteja intrinsicamente ligado, é difícil afirmar se o visual ilustra o conto ou se o conto ilustra o visual. Ou se a relação entre ambos é de complementaridade (Santaella e Nöth, 54).

O original Las Meninas (1656) pertence a um mundo no qual pinturas constituíam a única fonte de "verdade" disponível, considerando que a fotografia surgiria muito mais tarde. Velázquez, porém, pode ser considerado o precursor da idéia da fotografia, pois seus trabalhos são famosos pela sua representação "realista". Quanto à questão do ponto de vista, há muitos aspectos a serem considerados. Alguns críticos acreditam que Velázquez pintou a cena que viu no espelho à sua frente; outra possibilidade seria a de que ele a pintou baseado em seu imaginário, considerando que ele vivia na Corte e a cena deveria ser familiar em seu repertório. 
A terceira e mais provável possibilidade seria a de que a cena foi pintada através dos olhos do Rei e da Rainha, cujas imagens se refletem no espelho. Como objeto e sujeito de sua própria criação, Velázquez incluiu-se na Corte que admirava. Essa seria a cena que o Rei e a Rainha poderiam observar da posição onde estavam. Assim, Velázquez teria pintado “através" deles, do lado de fora do quadro, como em terceira pessoa, não endossando seu comprometimento. Além disso, ele parece ter pintado o que os monarcas gostariam de ver.

Margaret A. Rose, em seu livro Parody/Meta-Fiction, observa que o que talvez seja 'subversivo' nisso é o poder que Velázquez mostrou que a arte tem em reproduzir a hierarquia das realidades determinadas na Corte dentro dos tipos de representação usados nessa pintura (139). Minha argumentação seria a de que Velázquez, ao representar-se como pintor, criou uma ambigüidade que neutraliza seu compromisso com a ideologia das posições hierárquicas. Sua representação não é realmente sua. De fato, Foucault, ao analisar a obra, em seu Les Mots et les Choses, descreveu-a como uma representação da representação, e Margaret Rose acrescentou que o quadro

estabelece a hierarquia das realidades que refletem a hierarquia da corte, e que serão também refletidas no modo em que corte e monarca são representados... aqui novamente o objeto do trabalho artístico é visto como tendo ao menos duas funções - a de refletir o tema do artista e a de refletir sobre a natureza da realidade de sua representação. $(136,139)$

Velázquez problematiza a natureza da representação e especificamente o papel da representação na Corte, deixando assim abertos os canais interpretativos. Como Rose observa: como um espelho/quadro ambiguo, a imagem do Rei e da Rainha também comenta sobre as duas funções representacionais, reflexivas e simbólicas do trabalho artístico, como também a função representacional da corte terrena, como símbolo da hierarquia divina (139).

Entre os muitos pontos de vista sobre essa obra de Velázquez, duas suposições parecem ser relevantes para nossa 
análise. Enquanto alguns críticos afirmam que a hierarquia é o tema do trabalho, outros argumentam que é a própria representação o tema, afirmando que a preocupação de Velázquez com sua própria posição como pintor, o uso obscuro e enigmático do espelho e o direcionamento do ponto de vista exterior sustentam a hipótese de que a obra versa sobre a natureza e os usos da pintura, ou mais amplamente, da representação (Kahr 134).

Ambos os lados possuem argumentos válidos. Poder-se-ia então dizer que a ambigüidade tem um papel tão importante que, mesmo considerando que a obra remete às hierarquias, o método usado é sem dúvida auto-reflexivo.

O quadro não é somente reflexivo como também antecipa o que a fotografia seria no futuro. Numa fotografia, o autor poderia ter ajustado a câmera no self-timer e ter se posicionado junto à Infanta. Neste caso, estaria realmente na posição em que está, dentro do quadro. O que ele faz em Las Meninas é um processo trifásico: em primeiro lugar, ele pinta a cena de fora e, em segundo, pinta o Rei e a Rainha no espelho (durante uma das visitas ao cenário, o que deve ter acontecido muitas vezes). Finalmente, pinta a si próprio.

A representação nesse contexto é um mise-en-abîme refletido, considerando que a técnica empregada poderia ser a do reflexo do espelho. Sua técnica se torna, então, ambivalente. Por um lado, evita comprometimentos, se for considerado que o ponto de vista

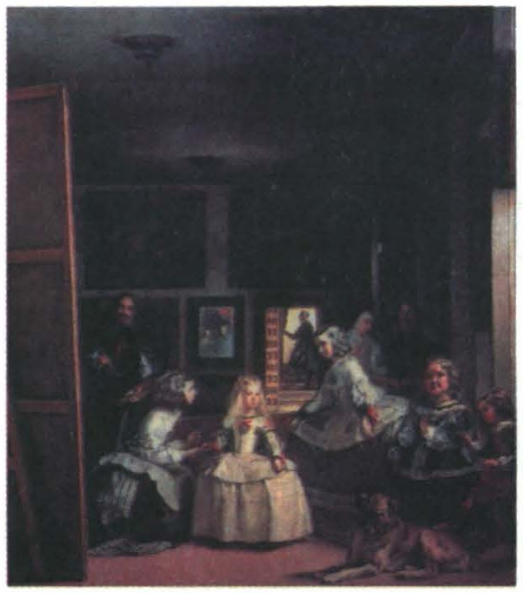
não pertence ao autor. Por outro lado, o autor está envolvido,

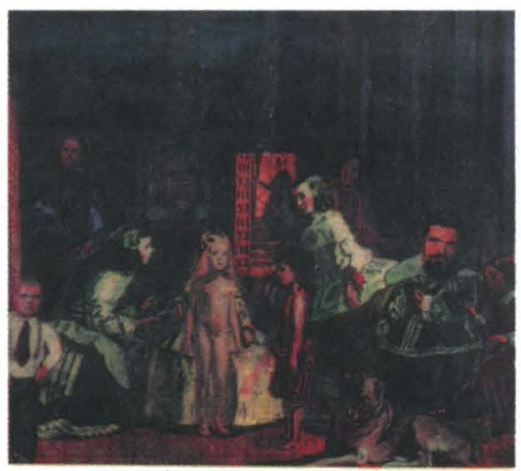


considerando que é ele quem está dentro do quadro. Entretanto, considerando que ele gostava da Corte e tinha lugar e status privilegiado nela, Velázquez talvez não tenha tido intenções politicas como o quadro pode sugerir. Sua proposta pode ter sido a de expressar sua preocupação sobre a própria representação, e seu enfoque criativo parece expressar esta preocupação.

As mudanças e adições feitas por Xavier-Dumke criam uma dimensão pós-moderna e permitem uma leitura anti-hierárquica.

Ao invés de Velázquez, agora vemos o próprio Dumke. Em vez do Rei e da Rainha, a face de Xavier. A anã Maribárbola foi substituida por Sebastian de Morra. Além disso, há um outro anão, $E^{2}{ }^{\prime}$, na parte de baixo do lado esquerdo, vestido à maneira contemporânea, e uma menina vestida de vermelho. A Infanta está desnuda cobrindo a imagem original, como se sua imagem "real" estivesse emergindo de seu vestido, sua essência desabrochando de seu casulo e seus pés se desvencilhando dos protetivos sapatos, combinando assim com os pés descalços da outra menina. Lado a lado, as duas meninas sugerem o título. Xavier, o escritor, é quem agora vê a cena, em lugar do Rei e da Rainha da Espanha. E é também ele quem re-inventa o cenário antigo com sua visão póscolonial que oferece novas conotações ao sistema real do século dezessete. Através de seus olhos, a cena que se descortina mostra uma "menina" privada de sua realeza que se equipara a uma outra menina similar. $\mathrm{O}$ texto que se segue revela o que o escritor brasileiro tinha em mente ao fazer essa colagem².

O texto de Xavier está escrito em partes, cada uma com quatro linhas, mas em três caracteres diferentes.

1. Valếncio Xavier, em sua entrevista escrita, disse ter incluído o anão do filme americano Freaks (1932), de Tod Browning.

2. Xavier mencionou, na entrevista escrita, que realmente viu duas crianças "fazendo sexo debaixo do Bondinho", e depois viu "umas menininhas seminuas tomando banho no chafariz da praça Osório". A outra história "é um fato acontecido em Curitiba de um menino morto e uma menina estuprada por um tarado sexual, e o menino jogado numa fossa sanitária". Xavier incluiu na parede "um quadro de duas crianças fazendo sexo", no lugar do quadro de Rubens "Minerva Punishing Arachne". Mais uma vezz, Xavier desconstrói a hierarquia do cenário original. 


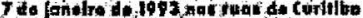

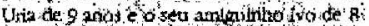

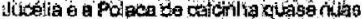

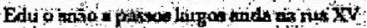

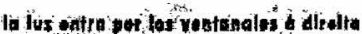

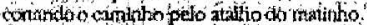

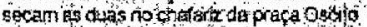
2 paxsinhos dele são tinuah dum dos teus

Y pör la parla -warta en ol maro al londo

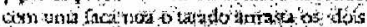
tar pouco a potäca transevia com untimentro o nuito passara pon th e presenctou a cena

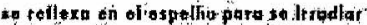

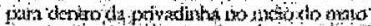
debaxo do bonderno corri gerte lá passando

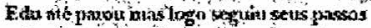

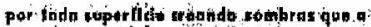

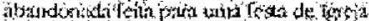

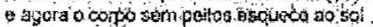

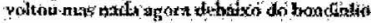

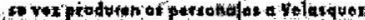

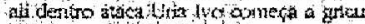

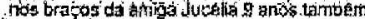

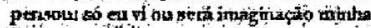

no lo finturaria la destrition dal dotall.

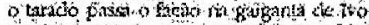

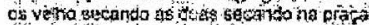

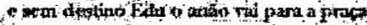

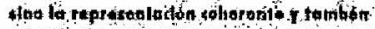

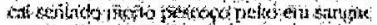
a) votho irais atrevido perigutia: iem fio?:

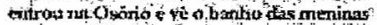

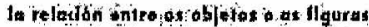

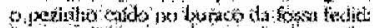
cur se aquecorna manha casa dzervila e cara hem füti de mano ositardlo provelite

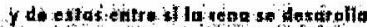

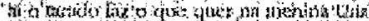

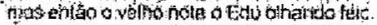

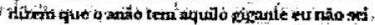

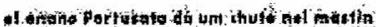

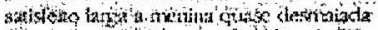
mog que nads fabu e val seirido do lito

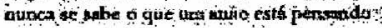

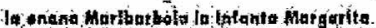
quando wolla a si salpelo tiuto yomirathita

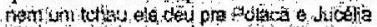

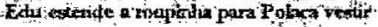

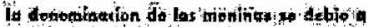

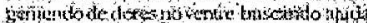
Polaca fala para duceliär viçe vial firar?

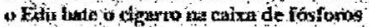

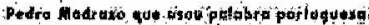

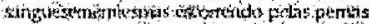
estat conversando com Edu so ela gue fala

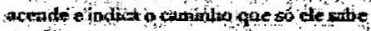

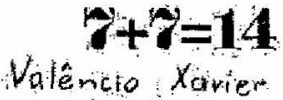

O leitor deve seguir as primeiras linhas de cada parte para ler a primeira parte, depois as segundas linhas para ler a segunda parte, e a terceira e quarta para ler a terceira parte. $O$ texto é fragmentado, com algumas partes em espanhol, outras em português, e outras misturando as duas ${ }^{3}$. Trata de crianças pobres nas ruas de Curitiba, capital do Paraná. Edu, o anão incluído no quadro, observa a cena e reprova o velho voyeur que tenta atrair as meninas do conto. A natureza fragmentada do texto leva a uma ambigüidade que sugere o contexto original e impede uma leitura coerente, coerência esta aqui usada em sentido convencional.

As três narrativas possuem pontos de conexão, mas as vozes não se mesclam, como se as três ações ocorressem ao mesmo tempo e tivessem como único elo de ligação o espaço que dividem, o cenário pobre de crianças sem roupa com suas vidas sem esperanças. Margarida, mais natural sem seu traje real, compartilha deste novo cenário onde as conotações hierárquicas falam mais explicitamente que em seu contexto original. Um leitor hipotético, desconhecedor do quadro original, diria que as damas de companhia estăo surpresas de ver a Infanta despida, lado a lado com uma meni-

3. Na entrevista escrita, Xavier explica que escreveu em "portunhol" porque o tftulo do quadro tambèm é nessa "Irngua", com a primeira palavra em espanhol e a segunda em português. 
na de rua. A presença da "outra" e a presença da princesa agora "não-princesa" fornecem ao espectador uma outra perspectiva em relação às damas de companhia, que parecem perplexas com o novo ambiente onde estão inseridas.

Michael Riffaterre, em seu artigo "Syllepsis", discute a relação classificada como "intratexto", onde o intertexto está parcialmente codificado com o texto e entra em conflito com esse por causa de suas incompatibilidades estilísticas ou semânticas (627). No caso de Dumke, parece que a incompatiblidade é semântica, no sentido de haver uma superposição de imagens. A Infanta original ainda está lá, e há outra Infanta despida, "colada"na original, não sendo assim a mesma menina que foi despida de suas roupas e sim um "clone", que é exatamente como ela. A Infanta não foi substituída pela outra, mas há uma segunda camada que conflitua semanticamente com o texto. A implicação semântica carrega uma crítica ideológica, não relacionada ao que o pintor original fez, mas ao que a sociedade daquela época representava em termos de hierarquias e poder.

A Infanta viaja no tempo e no espaço, para um mundo no qual não pode mais esconder seu corpo em vestes de realeza, mas ao mesmo tempo está lá, por debaixo de sua nova camada. Adicionando essa imagem colada, Dumke impõe uma nova leitura e um novo contexto para a Infanta, que parece, por compartilhar do cenário brasileiro, incorporar uma nova consciência sobre o mundo dos outros.

A auto-reflexividade do quadro original permanece e as mudanças produzem efeito. Desta vez, a cena é testemunhada pelo seu contador, não pelo Rei ou Rainha. O ilustrador é parte da cena, e os novos personagens são representantes do mundo pós-colonial, no qual as estruturas implícitas de poder e autoridade são reveladas. A Infanta, no centro da tela, foi desvestida e divide o espaço com "a outra". O título Las Meninas é suficientemente ambíguo para incluir mais meninas, meninas de um mundo não conhecido pela Infanta em seu habitat, mas certamente compartilhado agora, em seu novo ambiente. A nova linguagem é fragmentada: agrupa pedaços, vislumbres de vida. Enquanto Velázquez "capturou um momento vivo" de realeza, Xavier-Dumke oferecem um perspicaz "momento vivo" 
da vida diária dos menos privilegiados, momento este agora testemunhado pelos representantes de uma ordem mais velha, vindos de um mundo onde a pobreza mora do lado de fora de seus castelos. Essa nova narrativa, imbuída de preocupações sociais, é um aparato ideológico e um convite a novas leituras. Como Jameson cita:

Não é, naturalmente, acidental que hoje, em pleno pós-modernismo, a linguagem mais velha do "trabalho" — o trabalho de arte, a obra-prima - foi substituída em todos os campos pela linguagem do "texto", dos textos e da textualidade, bem diferente da antiga linguagem. Na nova linguagem a realização da forma orgânica ou monumental foi estrategicamente excluída. Tudo agora pode ser um texto nesse sentido (a vida cotidiana, o corpo, representações políticas), enquanto objetos que eram anteriormente denominados "trabalhos" podem agora ser relidos como grandes conjuntos ou sistemas de textos de vários tipos, superimpostos uns aos outros por meio das várias intertextualidades, sucessões de fragmentos, ou ainda, puro processo (daqui por diante chamado produção textual ou textualização). (77)

Este novo enfoque dado ao texto original inclui as preocupações pós-coloniais e pós-modernistas sobre "o outro" e as reflexões sociais relacionadas a essa nova tendência. Parece que há uma descentralização de elementos tais como poder, autoridade e lei, que tiveram que ser substituídos pelas formas menos hegemonizadas derivadas dos enfoques orientados para uma conscientização de classe e gênero trazida pela crítica pós-colonialista. Las Meninas de Xavier-Dumke não somente apresenta as vidas de "outras" meninas, mas também força a Infanta e suas damas de honra a testemunhar e a interagir nesse novo cenário. Xavier menciona que faz "uma espécie de jogo com o leitor" (entrevista escrita). De fato, seu texto interativo requer leitores ativos. Em seu texto, a primeira narrativa é relacionada a Velázquez (é sobre o texto que acompanha o quadro no Museu do Prado), a segunda é sobre um crime envolvendo duas crianças e um tarado sexual, e a terceira é sobre duas meninas nuas que se refrescam na fonte da praça e são seguidas por um velho. As três narrativas podem ser lidas separadamente 
ou interrelacionadas. Nesse novo contexto, as três são partes de outras vozes e é como se o passado pudesse testemunhar o presente, e não vice-versa.

O aspecto pós-moderno da narrativa é exatamente esse processo de updating que ocorre com os personagens da obra anterior quando se conscientizam e participam do novo contexto. A implicação de que a intertextualidade é a mera reconstrução de textos antigos e tem o objetivo de mostrar seu valor ou encontrar neles uma outra interpretação, então, não tem razão de ser no contexto atual, mesmo que muitos críticos insistam em impor leituras com esse enfoque. O texto de Xavier-Dumke traz ao mundo contemporâneo os personagens de Velázquez, ligando passado e presente de forma complementar. $O$ processo segue o que Landow comenta, que o processo de colagem ocorre quando os autores escrevem junto com textos de outros (38).

A auto-reflexividade atinge um ápice quando Xavier implicita que novos contextos não podem ser liberados do passado, não no sentido que não possam ser independentes, mas no sentido que seus textos refletem vozes aprendidas, vozes que não podem ser esquecidas e que estarão sempre no inconsciente coletivo, de uma maneira ou outra, explicita ou implicitamente.

Roland Barthes, em seu famoso artigo "The Death of the Author", faz comentários dizendo que o escritor só pode imitar o gesto que é sempre anterior, nunca original. Seu único poder é o de mixar textos, para contrapor uns aos outros... (novos textos) säo citações sem aspas (160). O texto de Xavier funciona como um comentário sobre a ilustração, se considerarmos o quadro como iniciador do contexto. Ao contrário, se decidirmos usar o texto como a etapa inicial, é o quadro que ilustra o texto. Devido às dificuldades em decidir qual é qual, conclui-se que ambos possuem uma outra dimensão: estão intrinsecamente ligados, da mesma maneira em que o contexto clássico é agora parte do novo cenário. A adição e superimposição de camadas não vêm sem conotações. A ordem patriarcal continua presente tanto no texto verbal quanto no não-verbal, mas agora oferece novas reflexões. Enquanto no mundo patriarcal a Infanta estava "protegida" contra o mundo exterior e escondida 
dentro de seus trajes, no novo contexto ela terá que se expor e interagir com outras meninas.

A primeira linha dos contos, em negrito, começa com uma data e um lugar, como um diário ou um documentário:

\section{7 de janeiro de 1993 nas ruas de Curitiba}

A transposição dos personagens de Velázquez para Curitiba endossa novamente as muitas análises e comentários feitos sobre luminosidade e iluminação no trabalho original. Para Dumke, a luz vem da porta aberta e da janela, se reflete no espelho e cria sombras que produzem os personagens. De fato, no quadro original, a luz ilumina o espelho que, por sua vez, ambiguamente reflete as imagens enevoadas e pouco distintas do Rei e da Rainha, que são os responsáveis pela produção dos personagens. As sombras que Xavier cita no texto são as imagens desenfocadas dos monarcas que vêem a cena. Se eles vêem a cena através de um espelho embaçado ou se as imagens foram pintadas propositalmente enevoadas é mais um ponto que contribui para a ambigüidade que o quadro original incorpora. Xavier comenta: a Velázquez no lo interessa la descricion del detalle sino la representación coherente y também la relación entre os objetos e as figuras y de estas entre si la cena se desarolla.

Novamente aqui, Xavier menciona a representação indistinta de alguns detalhes do trabalho original (as próprias mãos de Velázquez estão só rabiscadas) e do cenário doméstico que o pintor quis retratar. Enquanto Velázquez estava pintando Las Meninas, os monarcas por diversas vezes entraram na sala. Por isso, a cena poderia realmente ser o que eles viram. $O$ fim da primeira parte do texto é bastante fragmentado e assim se desenrola:

el enano Portusato dá um chute nel mastin la enana Maribarbola la infanta Margarita la denominación de las meninas se debio a Pedro Madrazo que usou palabra portuguesa 
Xavier implicita que o título original se refere à Infanta e à anã, o que é outro ponto ambíguo do trabalho original. No texto de Xavier há três meninas e na colagem de Dumke há uma menina ao lado da Infanta e a superposição da face de Morra na da anã Maribarbola. No final do texto, Xavier acrescenta: " $7+7=14$ ", que contém o elemento aditivo, implicitando que seu texto intertextual só pode ser uma adição ao de Velázquez, nunca uma redução ou desvalorização, ou mera interpretação de um clássico.

Se o quadro de Velázquez "brinca" com o sujeito/objeto da lente usando um ponto de vista indireto, o mesmo faz o texto de Xavier-Dumke. Neste último, é Xavier quem vê a cena e Dumke quem se torna o objeto da lente, mas que é ao mesmo tempo o sujeito que está compondo a cena. Dumke, como Velázquez, prepara a cena que Xavier quer ver. Mas Xavier é também o objeto da câmera, mesmo se só através do reflexo no espelho. Ao contrário do Rei e da Rainha, sua face é maior que a dos outros e essa desproporção quebra novamente a "coerência interna" da cena original, como Xavier menciona em sua narrativa. Apesar de que o texto original não pode ser considerado tradicional no sentido canônico, as inclusões e rupturas desconstroem a cena da realeza não só no nível estilístico. Ideologicamente, se as inclusões forçam a Infanta a dejxar sua posição privilegiada para outra mais participativa, Xavier também deve voltar no tempo e contemplar a cena real, analisando-a da mesma posição da qual os monarcas espanhóis participaram. A reversão de posições o força a entender o mundo de Velázquez. A posição de Dumke, por outro lado, é ainda mais comprometida. Ele está "dentro" da vestimenta sombria do pintor, vestimenta esta que mostra a cruz vermelha dos cavaleiros de Santiago. Porém, se levarmos em consideração que tudo é uma colagem, então Dumke não é mais um agente do rei, e sim uma face sobreposta que confronta o escritor e que vê a cena por detrás da mesma. De seu ângulo, a cena é ainda a mesma pintada por Velázquez, com a adição da menina em vermelho.

Para os espectadores, as camadas continuam. Colagens são, sem dúvida, mais exigentes em termos de audiência, especialmente 
neste caso, considerando que o texto original já é bastante dialógico e auto-reflexivo. O texto de Xavier-Dumke adiciona mais camadas e requer uma revisão de conceitos no que se refere à análise crítica. $O$ espectador tem que se adaptar ao novo cenário, romper com as barreiras da hierarquia e do centramento e trocar, como Hassan sugere, do código formal (linguagem padrão) ao idioleto. Hassan explica:

Como fenômeno artístico, filosófico e social, o pós-modernismo se torna aberto, lidico, optativo e provisório (aberto tanto em tempo quanto em estrutura e espaço), disjuntivo e indeterminado, formando um discurso de ironias e fragmentos, de "ideologia neutra" de ausências e fraturas, um desejo de difrações, uma invocação de silêncios complexos e articulados. (283)

Se a cena pós-moderna revela um mundo de indeterminâncias e fragmentos, o interjogo do texto de Xavier-Dumke sugere uma ponte ligando a transcendência de um clássico à imanência do cenário pós-moderno, de uma maneira "poliléptica", se usarmos o termo de Hassan (281).

O que acontece, então, quando um artista acrescenta tantas leituras a um texto já sobrecarregado de significados? Provavelmente as camadas adicionais irão problematizar ainda mais profundamente a questão da representação. Além disso, a ambigüidade deve alcançar um ponto no qual se torna protagonista do texto artístico. Silvio Gaggi acredita que o quadro de Velázquez

é o que hoje podemos chamar de desconstrução das convencôes da Renascença, por "explicar" o espaço clássico em tal maneira que deixa claro suas contradições e limitações... a complexidade e ambiguidade do problema se revela através do interjogo de posições (glances) dentro do texto, onde os papéis das figuras dentro do quadro e a da audiencia se envolvem numa série de relações complexas $e$ intercambiantes no jogo de observador e observado, sujeito e objeto, artista e audiência. (6) 
Que lugar ocupamos nós nos dois textos, então? Se ocuparmos o mesmo lugar de Felipe IV, Rei da Espanha, e sua segunda esposa, Mariana da Austria, dividiremos então o lugar, com Xavier, cuja imagem está refletida no espelho. De qualquer maneira, ocuparemos corpos habitados. Esse intercâmbio de elementos proporciona experiências de outras vidas aos personagens e leitores. O texto de XavierDumke força o Rei a "ver" o Outro, enquanto ambos, escritor e pintor, têm que habitar os corpos de Velázquez e do Rei e "ver"como eram suas vidas. Esses elementos intercambiantes trazem uma nova leitura, complementar e flexível. No contexto da estética da hipervenção ("hiper" no sentido de virtual e "venção" como invenção e intervenç̃̃o), os corpos realmente ocupam um hiper-espaço, esse espaço virtual previamente ocupado, onde níveis já pré-vistos serão relacionados e novas leituras serão alteradas por leituras anteriores.

A citação de Landow no começo deste ensaio menciona a intertextualidade de texto que se articula junto com outros textos. Xavier mescla dados factuais e fictícios, como a descrição formal do Museu do Prado interagindo com sua leitura pós-colonial. Além disso, algumas cenas descritas foram testemunhadas pelo autor (entrevista escrita) e associadas com o quadro de Velázquez. Nos contos, o autor co-habita outros corpos, ele é Edu, ele é o anão, ele é o voyeur. Na ilustração, ele é a imagem no espelho e também o anão.

Botanizando o asfalto, como diria Walter Benjamin, Xavier coleta seus fragmentos. Ele é o flâneur baudelaireano, a testemunha atenta de cenas da vida, mais tarde transpostas para seu universo ficcional. Mas, nesse caso, o que é "fiç̧ão" e o que é "não-ficção" é tão ambíguo quanto a questão da representação em seus textos. No caso específico do texto em questão, Xavier viu crianças e as reinventou. Sua "intervenção" ocorre em forma de colagem de novos participantes no tempo/espaço virtuais. Foucault disse que a ambigüidade está toda no espelho. Magritte pintou um olho e o denominou "le faux miroir" e Xavier permite que seus olhos vaguem e que sua imaginação crie. Xavier, como um flâneur baudelaireano da era pós-moderna, é o coletor de cenas, encontros e pensamentos, e é um voyeur que, como ele mesmo disse, escreve aquilo que gostaria de ler (entrevista escrita). 


\section{Bibliografia}

BARTHES, R. 1977. The Death of the Author. Image-Music-Text. NY: Hill \& Wang.

FOUCAULT, M. 1971. The Order of Things: An Archeology of the Human Sciences. NY: Random House.

GAGGI, S. 1989. Modern/Postmodern: A Study in Tewntieth-Century Arts and Ideas. Philadelphia: U of Pennsylvania P.

HASSAN, I. 1993. "Toward a Concept of Postmodernism." $A$ Postmodern Reader, ed. Natoli, Joseph and Linda Hutcheon. NY: State U of NY Press.

HUGHES, R, 1991. The Shock of the New. NY: McGraw-Hill.

JAMESON, F. 1991. Postmodernism, or, the Cultural Logic of Late Capitalism. Durham: Duke UP.

KAHR, M. M. 1976. Velásquez: The Art of Painting. NY: Harper \& Row.

LANDOW, G. P. 1994. ed. Hyper/Text/Theory. Baltimore: Johns Hopkins UP.

RIFFATERRE, M. 1980. "Syllepsis." Critical Inquiry, 6 (4), pp. 625638.

ROSE, M. 1979. A. Parody/Meta-Ficton. London: Croom Helm.

SANTAELLA, L. e NOTH, W. 1997. Imagem: Cogniçã̇o, semiótica, midia. São Paulo: Iluminuras.

ULMER, G. . "The Object of Post-Criticism." Postmodern Culture, ed. Hal Foster. London: Pluto Press, pp. 84-87.

XAVIER, V. 1993. Las Meninas. "Cultura G." Gazeta do Povo, Curitiba, PR., Brazil (Febr. 28), G1.

Interview. August 1998. Curitiba. 